\title{
"América", de Arthur Schnitzler
}

\author{
Guilherme da Silva Braga
}

Arthur Schnitzler nasceu em 1862 em Viena, na Áustria.

Em 1879, seguindo os passos do pai, começa a estudar medicina ao mesmo tempo em que dá os primeiros passos como escritor. Estreia no meio literário no ano seguinte, com a publicação do conto "Liebesleid der Ballerina".

Após concluir os estudos, começa a trabalhar como médico, porém dedicando-se cada vez mais à carreira de escritor.

Em 1897, escreve a peça Reigen, que causaria escândalo ao estrear em Berlim mais de vinte anos mais tarde devido ao modo direto como aborda a sexualidade.

Seu conto "Lieutenant Gustl”, publicado em 1900, foi pioneiro ao introduzir a técnica do monólogo interior na literatura alemã.

Graças aos retratos que pintou da vida e da sociedade na Viena do fim de século, Schnitzler entrou para a história da literatura como um dos mais importantes escritores da língua alemã.

Morreu em 21 de outubro de 1931, vítima de um derrame cerebral.

O conto "Amerika", traduzido a seguir, faz parte do livro Die Erzählenden Schriften, vol. 1 (Frankfurt am Main: S. Fischer, 1961). 
Guilherme da Silva Braga. "América", de Arthur Schnitzler

\section{Amerika}

Das Schiff landet; ich setze meinen Fuß auf den neuen Weltteil...

Der graue Herbstmorgen überschattet Meer und Land; noch schwankt alles unter mir; noch immer fühle ich den unruhigen Gang der Wogen... Aus dem Nebel erhebt sich die Stadt... Neben mir, mit offenen Augen, lebendig, hastet die Menge. Nicht das Fremde empfinden sie; nur das Neue. Ich höre, wie der oder jener vor sich hinflüstert: Amerika - als wenn er sich's nur recht einprägen wollte, daß er jetzt wirklich hier sei, so weit!...

Ich stehe allein am Ufer. Nicht an das neue Amerika denk' ich, von dem ich das Glück zu fordern habe, das mir die Heimat schuldig geblieben - ich denke an ein anderes.

Ich sehe jenes kleine Zimmer, so deutlich sehe ich es, als hätt' ich es gestern verlassen, nicht vor so vielen Jahren. Auf dem Tisch die Lampe mit dem grünen Schirm, der gestickte Lehnsessel in der Ecke. Kupferstiche hängen an der Wand; die Bilder verschwimmen im Schatten. Anna ist bei mir. Sie liegt mir zu Füßen, den Lockenkopf an mein Knie gelehnt; ich muß mich niederbeugen, um in ihre Augen zu sehen.

Wir haben aufgehört zu plaudern; der Abend schreitet weiter, und stille ist's im Gemach. Draußen beginnt es zu regnen, wir hören die Tropfen an die Fensterscheibe schlagen, langsam, schwer. Sie lächelt, und ich beuge mich zu ihrem Munde. Ich küsse ihre Lippen, ihre Stirn, ihre Augen, die sie geschlossen hat. Meine Finger spielen mit den feinen goldenen Haaren, die sich hinter ihren Ohren kräuseln. Ich schiebe sie zurück und küsse sie auf diese süße, weiße Hautstelle hinter dem Ohre. Sie schaut wieder auf und lacht. "Was Neues", flüstert sie, wie erstaunt. Ich halte meine Lippen fest hinter das Ohr gepreßt. Dann sage ich lächelnd: "Ja, was Neues habe ich entdeckt!" Sie lacht auf, und wie ein Kind fröhlich ruft sie aus: "Amerika!" 
Wie drollig war das damals! So toll und dumm! Ich sehe ihr Gesicht vor mir, wie es zu mir ausschaute mit den Schelmenaugen, und wie von ihren roten Lippen der Ruf erschallte: "Amerika!" Wie haben wir damals gelacht, und wie hat mich der Duft berauscht, der aus ihren Locken heraus über unser Amerika strömte...

Und bei dieser großartigen Benennung blieb es auch. Zuerst riefen wir es immer aus, wenn von den unzähligen Küssen einer sich hinters Ohr verirrte; dann flüsterten wir es - dann dachten wir es uns nur mehr; aber immer kam es zum Bewußtsein.

Eine Fülle von Erinnerungen steigt in mir auf. Wie wir einmal auf einer Anschlagsäule ein großes Schiff abgebildet sahen und, nähertretend, lasen: "Ab Liverpool - An New York - Ab Bremen An New York"... Wir lachten auf, mitten auf der Straße, und sie behauptete ganz laut, während Leute herumstanden: “Du, wir reisen heute noch nach Amerika!" Die Leute schauten sie ganz verwundert an; besonders ein junger Mann mit einem blonden Schnurrbart, der noch dazu lächelte. Mich ärgerte das sehr, und ich dachte: Ja, der möchte wohl mitreisen...

Dann saßen wir einmal im Theater, ich weiß nicht mehr, bei welchem Stück, da sprach irgendeiner auf der Bühne von Kolumbus. Es war ein Stück in Jamben, und ich entsinne mich des Verses: "und da Kolumbus auf die Brücke trat..." Anna stieß mit ihrem Arm leicht an den meinen; ich sah sie an und verstand ihren geringschätzigen Blick. Der arme Kolumbus... als wenn der das wahre Amerika entdeckt hätte! Als wir nach dem Theater in einem Weinhause saßen, da sprachen wir viel von dem guten Manne, der sich so viel eingebildet hatte auf sein armseliges Amerika. Eigentlich bedauerten wir ihn. Ich konnte mir ihn lange Zeit hindurch nicht anders vorstellen, als mit trauervollem Blicke an der Küste seines neuen Weltteiles stehend, sonderbarerweise mit einem Zylinder und einem ganz modernen Überzieher, und enttäuscht den Kopf schüttelnd. Einmal zeichneten wir ihn gemeinschaftlich auf der Marmorplatte eines Kaffeehaustisches und fanden immer neue Details. Sie bestand darauf, daß er eine Zigarre rauchen müsse; 
außerdem trug der große Entdecker auf unserem Gemälde einen Regenschirm, und sein Zylinder war eingedrückt - natürlich - wegen der Meuterer. So wurde Kolumbus für uns die humoristischste Figur der ganzen Weltgeschichte. Wie toll! Wie dumm!...

Und nun stehe ich mitten in der großen, kalten Stadt. Ich bin in dem falschen Amerika und träume von meinem süßen, duftenden Amerika da drüben... Und wie lange das schon her ist! Viele, viele Jahre. Ein Schmerz, ein Wahnsinn kommt über mich, daß so etwas unwiederbringlich verloren ist. Daß ich nicht einmal weiß, wo eine Kunde von mir, wo ein Brief sie treffen könnte - daß ich nichts, gar nichts mehr von ihr weiß...

Weiter hinein in die Stadt führt mich mein Weg, und mein Gepäckträger folgt mir. Ich bleibe einen Augenblick stehen, schließe die Augen, und durch ein seltsames trügerisches Spiel der Sinne umfängt mich derselbe Duft, wie er an jenem Abend von Annas Locken über mich wehte, da wir Amerika entdeckten... 
Cadernos de Literatura em Tradução, n. 10, p. 157-163

\section{América}

O navio aporta; ponho os pés no Novo Mundo...

A manhã cinza de outono encobre o mar e a terra; o mundo balança sob os meus pés; ainda sinto o movimento incansável das ondas... A cidade se ergue em meio à neblina... Ao meu lado, de olhos bem abertos, a multidão irrequieta se apressa. Eles não têm a impressão do estrangeiro; apenas da novidade. Escuto enquanto aqui e acolá alguém sussurra: "América" - como se quisesse convencerse de que agora estamos mesmo aqui, tão longe!...

Estou sozinho na orla. Não é nesta nova América que eu penso, onde ainda tenho de exigir a felicidade que a pátria ficou me devendo - é numa outra.

Vejo o pequeno quartinho, vejo-o com tanta clareza que é como se eu tivesse saído de lá ontem, e não há muitos e muitos anos. Sobre a mesa, o abajur verde; no canto, a poltrona bordada. Na parede estão penduradas gravuras; as imagens nadam na penumbra. Anna está comigo. Ela está aos meus pés, com os cachos apoiados no meu joelho; preciso me inclinar para ver seus olhos.

Nós paramos de conversar; a noite se adensa e a salinha está envolta em silêncio. Lá fora começa a chover; escutamos as gotas batendo na vidraça, lentas, pesadas. Anna sorri, e eu me inclino até seus lábios. Beijo-lhe a boca, a testa e os olhos, que ela fechou. Meus dedos brincam nos delicados fios dourados que se enroscam atrás de suas orelhas. Eu os afasto e beijo a pele doce e alva que ali se esconde. Anna abre os olhos e ri. "Um lugar novo", cochicha ela, como estivesse surpresa. Mantenho os lábios colados atrás de sua orelha. Então digo, com um sorriso: "É, descobri um lugar novo!". Ela ri, e diz, com um jeito de criança alegre: "América!".

Como aquilo foi engraçado! Que loucura, que bobagem! Vejo seu rosto diante de mim, lembro do olhar travesso de Anna quando seus lábios rubros gritaram: "América!". Como nós rimos, e como 
me embriaguei no perfume que recendia daqueles cachos por sobre a nossa América...

E esse nome grandioso perdurou. De início nós sempre ríamos quando, em meio a beijos incontáveis, um deles pousava-lhe atrás da orelha; depois cochichávamos - logo não fazíamos mais do que pensar; mas aquilo nunca passava despercebido.

Ocorrem-me várias lembranças. Certa vez vimos um anúncio com um navio enorme e, ao chegar mais perto, lemos: “De Liverpool - a Nova York - de Bremen - a Nova York"... Começamos a rir em plena rua, e ela declarou em voz alta, mesmo com toda a gente ao redor: "Escute, ainda hoje nós vamos para a América!". As pessoas olharam para ela meio surpresas; em especial um jovem de bigode loiro, que ainda por cima sorriu. Fiquei irritado e pensei: Ah, esse aí queria ir junto...

Em outra ocasião estávamos no teatro; não me lembro o que assistíamos, mas no palco alguém falava de Colombo. A peça era escrita em iambos, e agora acode-me o verso: “- e então Colombo a ponte atravessou...". Anna deu-me um leve cutucão no braço; olhei para ela e logo entendi seu olhar desdenhoso. Pobre Colombo... Como se ele houvesse descoberto a verdadeira América! Terminada a apresentação, fomos tomar vinho em uma adega, onde falamos um bocado sobre aquele bom homem que tanto se gabara de sua pobre América. Na verdade, sentíamos pena dele. Por muito tempo fui incapaz de imaginá-lo senão como um homem de olhar triste, em pé na costa do Novo Mundo, usando uma improvável cartola e um sobretudo moderno, desiludido, balançando a cabeça. Uma vez nós dois desenhamos Colombo em uma mesa de mármore no café, acrescentando vários detalhes. Anna decidiu que ele deveria estar fumando um charuto; ademais, o grande explorador também carregava, nesse desenho, um guarda-chuva, e sua cartola estava amassada - é claro - por causa dos amotinados. E assim Colombo tornou-se, para nós, a figura humorística por excelência da história universal. Que loucura! Que bobagem!... 
Agora estou no meio da cidade grande e fria. Estou na América falsa e sonho com a doçura e o perfume da minha América distante... Faz tanto tempo! Muitos, muitos anos. Uma dor, uma loucura toma conta de mim por eu ter perdido algo irrecuperável... Por eu não saber sequer para onde mandar notícias nem onde uma carta minha pudesse encontrá-la - por já não saber mais nada, absolutamente nada a respeito dela..

Meu caminho avança cidade adentro, e o carregador me segue. Detenho-me por um instante, fecho os olhos e, graças a uma ilusão fugaz dos sentidos, uma nuvem de perfume me envolve; o mesmo perfume que naquela noite soprou dos cachos de Anna, quando descobrimos a América... 